\title{
Clinicopathological Features and Type of Surgery for Lynch Syndrome: Changes during the Past Two Decades
}

\author{
II Tae Son, MD'1 \\ Duck-Woo Kim, MD, PhD',2 \\ Seung-Yong Jeong, MD, $\mathrm{PhD} 2,3$ \\ Young-Kyoung Shin, $\mathrm{PhD}^{2}$ \\ Myong Hoon Ihn, MD ${ }^{1}$ \\ Heung-Kwon Oh, MD 1 \\ Sung-Bum Kang, MD, $\mathrm{PhD}^{1}$ \\ Kyu Joo Park, MD, PhD ${ }^{3}$ \\ Jae Hwan Oh, MD, PhD ${ }^{4}$ \\ Ja-Lok Ku, PhD² \\ Jae-Gahb Park, MD, PhD2,4
}

\begin{abstract}
Purpose
The Korean Hereditary Tumor Registry, the first and one of the largest registries of hereditary tumors in Korea, has registered about 500 families with hereditary cancer syndromes. This study evaluates the temporal changes in clinicopathologic features and surgical patterns of Lynch syndrome (LS) patients.
\end{abstract}

\section{Materials and Methods}

Data on 182 unrelated LS patients were collected retrospectively. The patients were divided into the period 1 group (registered in 1990-2004) and 2 (registered in 2005-2014). The clinical characteristics of the two groups were compared to identify changes over time.

\section{Results}

The period 1 group included 76 patients; the period 2 group, 106 patients. The mean ages at diagnosis were 45.1 years (range, 13 to 85 years) for group 1 and 49.7 years (range, 20 to 84 years) for group 2 ( $p=0.015)$. The TNM stage at diagnosis did not differ significantlyperiod 1 group: stage $0-\mathrm{I}(\mathrm{n}=18,23.7 \%)$, II $(n=37,48.7 \%)$, III $(n=19,25.0 \%)$, and IV ( $n=2$, 2.6\%); period 2 group: stage $0-\mathrm{I}(\mathrm{n}=30,28.3 \%)$, II $(n=35,33.0 \%)$, III $(n=37,34.9 \%)$, and IV $(n=4,3.8 \%)$. Extended resection was more frequently performed $(55 / 76,72.4 \%)$ in the period 1 group than period $2(49 / 106,46.2 \%)(p=0.001)$.

\section{Conclusion}

Colorectal cancer in patients with LS registered at the Korean Hereditary Tumor Registry is still diagnosed at an advanced stage, more than two decades after registry's establishment. Segmental resection was more frequently performed in the past decade. A prompt nationwide effort to raise public awareness of hereditary colorectal cancer and to support hereditary cancer registries is required in Korea.
Correspondence: Duck-Woo Kim, MD, PhD Department of Surgery,

Seoul National University Bundang Hospital, 82 Gumi-ro 173beon-gil, Bundang-gu,

Seongnam 13620, Korea

Tel: 82-31-787-7101

Fax: 82-31-787-4078

E-mail: kdw@snubh.org

\section{Received March 4, 2015}

Accepted April 16, 2015

Published Online May 26, 2015

*The abstract of this article was presented at the 18th Annual Meeting of the Collaborative Group of the Americas on Inherited Colorectal Cancer in New Orleans, LA, USA, on September 15-16, 2014.

\section{Key words}

Registration, Hereditary nonpolyposis colorectal neoplasms, Lynch syndrome 


\section{Introduction}

Lynch syndrome (LS) is an autosomal-dominant genetic predisposition to cancer, accounting for about 1\%-5\% of colorectal cancer (CRC) [1]. LS is caused by an inactivating germline mutation in a mismatch repair (MMR) gene, including MLH1, MSH2, MSH6, PMS2, and EPCAM. LS entails a lifetime CRC risk of $60 \%-80 \%$ [2] and displays distinct clinical phenotypes, such as early age of cancer onset, predominance of proximal CRC, excessive synchronous and metachronous tumors, and various extra-colonic tumors of the endometrium, ovary, stomach, small bowel, pancreas, biliary tree, brain, and urothelium [3]. The Amsterdam Criteria for a diagnosis of LS were developed by the International Collaborative Group on Hereditary Non-Polyposis Colorectal Cancer (ICG-HNPCC) in 1991, and were modified in 1999 because they included limited extra-colonic tumors and were relatively insensitive to germline MMR mutations [4]. The Bethesda Criteria, which are more sensitive, are used together with the patient's microsatellite instability (MSI) status to identify those who qualify for MMR mutation analysis [5]. Both clinical diagnosis based on the Amsterdam Criteria and genetic diagnosis based on an MMR mutation analysis identify LS effectively.

Since the establishment of the first hereditary colorectal tumor registry in 1925 at St Mark's Hospital, London, UK, the registration and systematic care of individuals with hereditary colorectal tumors has increased globally and been extended to families with familial adenomatous polyposis, LS, Peutz-Jeghers syndrome, and various rare hereditary gastrointestinal cancer syndromes [6]. Well-organized registries have improved the effective management of patients with hereditary CRC and their relatives. Furthermore, registry-based screening reduces the incidence and mortality of CRC considerably in Western countries [7-11]. However, such large-scale population-based screening and the early control of hereditary cancer can be maintained only by the activity of a national registry rather than single institutional or regional registries $[10,12]$. The importance of central organization and ongoing funding in the management of hereditary cancer syndromes is well recognized [12]. In contrast, there is no report on the performance of hereditary cancer registry in Asian populations.

The Korean Hereditary Tumor Registry (KHTR) was established in 1993 as the first such registry in Korea. The KHTR performs many important functions, including the registration of new patients with hereditary tumors, mutational screening of the genes responsible for specific hereditary tumors, and surveillance of at-risk relatives with presymptomatic genetic diagnoses. The KHTR screens the genes responsible for hereditary tumors in various organs, including the colon, rectum, breast, ovary, stomach, eye, brain, bone, adrenal gland, and kidney [6]. These activities are performed in close cooperation with many referring hospitals. The KHTR contains information on 186 different families affected by LS or suspected of LS, 98 different families affected by familial adenomatous polyposis, and many families with various other hereditary tumors, and it is currently one of the largest hereditary tumor registries in Korea.

This study evaluated the changes in various clinical features of LS patients in the registry in terms of the early detection of CRC and the appropriate management of these patients over the past two decades, since the establishment of the KHTR.

\section{Materials and Methods}

\section{Study population}

Patients fulfilling the Amsterdam II Criteria proposed by the ICG-HNPCC were selected by pedigree review [13] from 567 individuals in 186 different families affected with LS or suspected LS patients registered in the KHTR. Patients not fulfilling the criteria, but whose genetic analysis confirmed a germline mutation in an MMR gene were also included. In addition to pedigree analyses, MSI testing is routinely performed in clinical practice for all CRC patients in major referring hospitals associated with our registry. Five microsatellite markers (BAT-25, BAT-26, D2S123, D5S346, and D17S250) are used to analyze paired normal and tumor DNAs for MSI. Tumors were classified as MSI-high when at least two of the five markers displayed novel bands, MSI-low when additional alleles were found with one of the five markers, and stable microsatellite when all microsatellite markers examined displayed identical patterns in both tumor and normal tissues. Genetic counseling is offered to patients with CRC showing MSI, and genetic testing is provided with the consent of the patient. Patients with CRC showing MSI are also tested for LS based on the results of genetic testing. The clinicopathologic data for all patients in the present study were available, including their demographic data, informative pedigree, details of treatment, and pathological stage of CRC.

The study patients are divided into two period groups: the period 1 group included patients diagnosed with LS in 19902004 and the period 2 group included patients diagnosed with LS in the past decade, 2005-2014. The clinical characteristics of the two groups were compared to identify any changes that have occurred since the foundation of the 
KHTR. The type of surgery used was classified into extended resection (subtotal colectomy, total colectomy, or restorative proctocolectomy with ileal pouch-anal anastomosis) and segmental resection (right hemicolectomy, transverse colectomy, left hemicolectomy, anterior resection, low anterior resection, ultralow anterior resection, Hartmann's operation, or abdominoperineal resection). A histological examination was performed by a pathologist experienced in colorectal and oncological pathology. The extent of the disease at diagnosis was classified by TNM stage (the seventh edition of the American Joint Committee on Cancer staging manual) [14]. A chi-squared test or Fisher exact test (where appropriate) was used for the inference of proportions. Null hypotheses of no difference were rejected if $\mathrm{p}$-values were less than 0.05 . All statistical analyses were performed using SPSS ver. 18.0 (SPSS Inc., Chicago, IL).

\section{Results}

One hundred and seventy-one LS patients fulfilling the Amsterdam II Criteria for genetic testing during the study period were identified. Genetic testing for MMR mutations (in MLH1, MSH2, PMS2, or MSH6) was performed in 141 of these 171 patients and germline mutations were identified in $60(42 \%)$. Genetic testing confirmed MMR germline mutations in 11 of the 396 patients with no known family history, but who were close to the diagnostic clinical criteria, or had CRC with MSI-high. Seventy-one patients in this study carried MMR gene mutations. The distribution of germline mutations among MMR genes and mutation type (frameshift, missense) were not different between period groups. The study analyzed 182 LS patients.

The period 1 group included 76 patients and the period 2 group included 106 patients. The mean age at diagnosis was 45.1 years (range, 13 to 85 years) for period 1 and 49.7 years (range, 20 to 84 years) for period 2 ( $p=0.015$ ). The two groups had similar sex distributions. The clinicopathologic characteristics of each group are listed in Table 1. The most common tumor site was the rectum $(n=21,27.6 \%)$ in the period 1 group and the sigmoid colon $(n=33,31.1 \%)$ in the period 2 group. However, the predominance of a proximal location was the same in the two groups. There was no change in the cancer stage at diagnosis throughout the study period. The extent of disease at diagnosis in the LS patients did not differ significantly over time $(p=0.186)$ (Table 1$)$. Extended resection was performed in 55 patients $(72.4 \%)$ and segmental resection in 21 patients $(27.6 \%)$ of the period 1 group, and extended resection in 49 patients $(46.2 \%)$ and segmental resection in $57(53.8 \%)$ of the period 2 group $(\mathrm{p}=0.003)$
(Table 2). This study shows that laparoscopic surgery is widely used for LS CRC; the penetrance of laparoscopy in the period 2 group was $31.3 \%$. The relationships between the pattern of surgery and other factors were evaluated. Segmental resection was more frequently performed in patients registered in the KHTR in the past decade, in patients with rectal cancer, or in older patients whose age at diagnosis was over 60 (Table 3).

\section{Discussion}

CRC is one of the most common causes of cancer-related death in Korea and its incidence has increased steeply over the past 25 years [6]. Because CRC displays familial clustering in up to $20 \%-30 \%$ of all cases, this increase makes it even more important to recognize hereditary CRC syndrome in Korea [15]. Detecting hereditary CRC not only allows the provision of the appropriate management to patients with hereditary CRC, but also the identification of high-risk individuals among their family members. Offering them standard cancer surveillance can prevent advanced hereditary-CRC-syndrome-associated malignancies in affected familial members [16]. Only a well-organized registry can accomplish these activities for the families affected by hereditary CRC syndrome [6].

Registry-based screening for LS is crucial, and over the past two decades nationwide or regional registries have been established in Finland, Germany, Canada, Denmark, and the Netherlands [11]. Large-scale registration in these countries allowed practical advances in improving public health. The Danish HNPCC Registry supervises the central registration of data on all families with hereditary CRC, and reports that because of screening, LS patients with stage III CRC have a better overall survival rate than those with sporadic CRC [17]. The mortality of CRC has been reduced] by a large-scale surveillance program for LS in the Netherlands [18]. A recent systematic review reported that registry-based screening is essential for reducing the incidence and mortality of CRC in patients with LS, and the authors highlighted the importance of funding and managerial support for hereditary CRC registries [13]. The accumulation of extensive data on patients with hereditary cancer makes it possible to conduct largescale research, providing medical evidence that can greatly improve clinical practice [12]. In several countries, including Finland (Finnish Hereditary Colorectal Cancer Registry), Germany (German HNPCC Consortium), Canada (Hereditary Cancer Registry), and the Netherlands (Dutch Cancer Registry), the number of registered LS families with a known mutation exceeds 2,000 together with about 10,000 individ- 
Table 1. Lynch syndrome patient characteristics

\begin{tabular}{|c|c|c|c|}
\hline Variable & Group $1($ period $1990-2004)(n=76)$ & Group 2 (period 2005-2014) (n=106) & p-value \\
\hline Age, mean (range, yr) & $45.1(13-85)$ & $49.7(20-84)$ & 0.015 \\
\hline \multicolumn{4}{|l|}{ Sex } \\
\hline Male & $51(67.1)$ & $54(50.9)$ & 0.034 \\
\hline Female & $25(32.9)$ & $52(49.1)$ & \\
\hline \multicolumn{4}{|l|}{ Location } \\
\hline Proximal colona) & $31(40.8)$ & $37(34.9)$ & 0.093 \\
\hline Distal colon ${ }^{\mathrm{b})}$ & $23(30.3)$ & $37(34.9)$ & \\
\hline Rectum & $21(27.6)$ & $22(20.8)$ & \\
\hline Multiple & $1(1.3)$ & $10(9.4)$ & \\
\hline \multicolumn{4}{|l|}{ Histologic differentiation $^{c}$} \\
\hline Well differentiated & $15(19.7)$ & $17(16.0)$ & 0.435 \\
\hline Moderately differentiated & $17(22.4)$ & $76(71.7)$ & \\
\hline Poorly differentiated & $5(6.5)$ & $6(5.7)$ & \\
\hline Mucinous adenocarcinoma & $8(10.5)$ & 0 & \\
\hline Signet cell ring carcinoma & $1(1.3)$ & 0 & \\
\hline \multicolumn{4}{|l|}{ Laparoscopic approach } \\
\hline Yes & 0 & $33(31.2)$ & 0.001 \\
\hline No & $76(100)$ & $73(68.8)$ & \\
\hline \multicolumn{4}{|l|}{ Tumor extension } \\
\hline T0 & $4(5.3)$ & $3(2.8)$ & 0.585 \\
\hline T1 & $9(11.8)$ & $15(14.2)$ & \\
\hline $\mathrm{T} 2$ & $7(9.2)$ & $17(16.0)$ & \\
\hline $\mathrm{T} 3$ & $46(60.5)$ & $60(56.6)$ & \\
\hline $\mathrm{T} 4$ & $10(13.2)$ & $11(10.4)$ & \\
\hline \multicolumn{4}{|l|}{ Nodal metastasis } \\
\hline N0 & $55(72.4)$ & $65(61.3)$ & 0.109 \\
\hline N1 & $18(23.6)$ & $28(26.4)$ & \\
\hline N2 & $3(4.0)$ & $13(12.3)$ & \\
\hline \multicolumn{4}{|l|}{ Metastasis } \\
\hline M0 & $74(97.4)$ & $102(96.3)$ & 0.708 \\
\hline M1 & $2(2.6)$ & $4(3.7)$ & \\
\hline \multicolumn{4}{|l|}{ TNM stage } \\
\hline 0-I & $18(23.7)$ & $30(28.3)$ & 0.186 \\
\hline II & $37(48.7)$ & $35(33.0)$ & \\
\hline III & $19(25.0)$ & $37(34.9)$ & \\
\hline IV & $2(2.6)$ & $4(3.8)$ & \\
\hline
\end{tabular}

Values are presented as number (\%). ${ }^{a}$ Proximal to the splenic flexure, ${ }^{b}$ Distal to the splenic flexure, ${ }^{\mathrm{c}}$ Missing data; 30 patients in group 1 and seven patients in group 2.

uals who are confirmed mutation carriers [8].

However, no reduction in the extent of the disease at diagnosis has been observed in the CRC patients registered at the KHTR since its foundation. The proportion of patients with advanced (regional or distant) disease at diagnosis in the period 2 group was still substantial $(38.7 \%$ in the period 2 group vs. $27.6 \%$ in period 1 , respectively), although the difference was not significant. The registry has been used in the management of hereditary colon cancer in collaboration with many cancer clinics over the past two decades. How- ever, this study shows that the KHTR, an institution-based registry, has not improved the overall mortality or early detection of LS patients. As an institution-based registry, it is impossible for the KHTR to perform nationwide registration and systematic management for LS patients. To reduce the incidence and mortality of CRC in patients with hereditary CRC, including familial adenomatous polyposis and LS, registration and screening must extend beyond the regional registry level or a single institutional registry $[11,19]$. Patients with LS should be notified of a regional genetics registry and 
Table 2. Surgical method comparison between period 1 group and period 2 group

\begin{tabular}{|c|c|c|c|}
\hline Operation type & Group 1 (period 1990-2004) $(n=76)$ & Group 2 (period 2005-2014) (n=106) & p-value ${ }^{a)}$ \\
\hline Standard operation & $55(72.4)$ & $49(46.2)$ & 0.001 \\
\hline Subtotal colectomy & 32 & 23 & \\
\hline Total colectomy & 16 & 21 & \\
\hline Total proctocolectomy & 7 & 5 & \\
\hline Segmental resection & $21(27.6)$ & $57(53.8)$ & \\
\hline Right hemicolectomy & 6 & 19 & \\
\hline Transverse colectomy & 2 & 0 & \\
\hline Left hemicolectomy & 1 & 2 & \\
\hline Anterior resection & 2 & 15 & \\
\hline Low anterior resection & 8 & 12 & \\
\hline Ultralow anterior resection & 0 & 4 & \\
\hline Hartmann's operation & 0 & 1 & \\
\hline Abdominoperineal resection & 1 & 4 & \\
\hline Segmental resection of colon & 1 & 0 & \\
\hline
\end{tabular}

Values are presented as number (\%). ${ }^{a}$ Using Fisher exact test.

Table 3. Factors affecting surgical method

\begin{tabular}{|c|c|c|c|c|}
\hline Variable & Standard operation $(n=104)$ & Segmental resection $(n=78)$ & Total & p-value \\
\hline \multicolumn{5}{|l|}{ Period } \\
\hline Group 1 (1990-2004) & $55(72.4)$ & $21(27.6)$ & 76 & 0.001 \\
\hline Group 2 (2004-2014) & $49(46.2)$ & $57(53.8)$ & 106 & \\
\hline \multicolumn{5}{|l|}{ Diagnosis of LS } \\
\hline Fulfilling $\mathrm{AC}^{\mathrm{a})}$ & $100(58.5)$ & $71(41.5)$ & 171 & 0.131 \\
\hline Genetic testing ${ }^{\mathrm{b})}$ & $4(36.4)$ & $7(63.6)$ & 11 & \\
\hline \multicolumn{5}{|l|}{ Location of $\mathrm{CRC}^{\mathrm{c}}$} \\
\hline Colon & $64(50.0)$ & $64(50.0)$ & 128 & 0.033 \\
\hline Rectum & $13(30.2)$ & $30(69.8)$ & 43 & \\
\hline \multicolumn{5}{|l|}{ Age of diagnosis $(y r)^{b)}$} \\
\hline$\leq 60$ & $94(61.8)$ & $58(38.2)$ & 152 & 0.005 \\
\hline$>60$ & $10(33.3)$ & $20(66.7)$ & 30 & \\
\hline
\end{tabular}

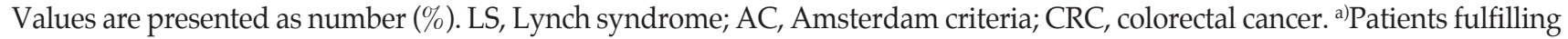
the Amsterdam II Criteria by the International Collaborative Group on Hereditary Non-Polyposis Colorectal Cancer, ${ }^{\text {b) Mu- }}$ tation screening for mismatch repair gene (MLH1 and MSH2), c)Excluded 11 patients with multiple tumors.

managed in the context of that registry [20]. As regional registries are extended, not only can patients with newly detected LS-associated cancer be provided with genetic counseling and testing at their regional or institutional registry, their at-risk relatives can be invited to genetic counseling and risk assessment, predictive testing, and appropriate screening at their own regional registry. It may also be easier to raise public awareness of hereditary CRC throughout the country. It is highly significant that only about one third of LS patients develop the disease de novo, rather than inheriting the pathogenic MMR mutation from their parents [21]. Despite this, most patients with hereditary CRC are still managed on an individual basis in Korea.

Extended resection, such as subtotal colectomy, is generally favored over segmental resection in the curative surgery for LS patients with CRC because segmental resection entails a greater risk of synchronous and metachronous CRC. A retrospective study of LS patients with rectal cancer who underwent segmental resection found that the cumulative risk of metachronous colon cancer was $19 \%$ at 10 years, $47 \%$ 
at 20 years, and $69 \%$ at 30 years after surgical resection [22]. Recent guidelines limit the use of segmental resection only to those patients for whom total colectomy is unsuitable, and only if regular postoperative surveillance is conducted [21]. However, the appropriate surgery for each individual with LS is an open question. Rodriguez-Bigas and Moeslein [23] suggested that treatment must be individualized for each patient because there has been no prospective or randomized control study suggesting that extended resection confers a survival benefit compared with segmental resection. Another study suggested that less extensive surgery should be considered for elderly patients, because the increase in life expectancy achieved with total colectomy rather than segmental resection in LS patients aged 67 years was only 0.3 years [24]. For rectal cancer in LS, there is still debate on total proctocolectomy as a standard procedure. The risk of metachronous colon cancer was reported as 15\%-54\% after segmental resection of rectal cancer, although quality of life concerns and defecation problems are substantial [22]. The present study indicates that segmental resection is more frequently performed in patients with rectal cancer, or in older patients whose age at diagnosis was over 60 . Although not statistically significant, it is interesting that seven of 11 patients $(63.6 \%)$ diagnosed with LS by genetic testing underwent segmental resection (Table 3). The difficulties inherent in preoperative genetic testing in daily clinical practice may affect its contribution to surgical decision making. This study shows that increasing numbers of surgical procedures are currently performed with laparoscopy. As evidence of the safety and feasibility of the laparoscopic approach in CRC surgery increases, expert opinion on the surgical management of CRC in LS patients is that surgical procedures can be performed with either open or minimally invasive techniques $[2,23]$.

\section{Conclusion}

In conclusion, CRC in patients with LS and registered at the KHTR is still diagnosed at an advanced stage, more than two decades after the registry's establishment. This indicates that the impact of a single institutional registry on the screening and surveillance of hereditary tumors is limited. Segmental resection rather than extended resection has been performed more frequently in the past decade. A prompt nationwide effort to raise public awareness of hereditary $\mathrm{CRC}$ and to increase the support for registries is required in Korea.

\section{Conflicts of Interest}

Conflict of interest relevant to this article was not reported.

\section{Acknowledgments}

This study was supported by a grant from the National Cancer Center (number 1420180).

\section{References}

1. Aaltonen LA, Salovaara R, Kristo P, Canzian F, Hemminki A, Peltomaki $\mathrm{P}$, et al. Incidence of hereditary nonpolyposis colorectal cancer and the feasibility of molecular screening for the disease. N Engl J Med. 1998;338:1481-7.

2. Vasen HF, Moslein G, Alonso A, Bernstein I, Bertario L, Blanco I, et al. Guidelines for the clinical management of Lynch syndrome (hereditary non-polyposis cancer). J Med Genet. 2007;44:353-62.

3. Lynch HT, de la Chapelle A. Hereditary colorectal cancer. N Engl J Med. 2003;348:919-32.

4. Vasen HF, Watson P, Mecklin JP, Lynch HT. New clinical criteria for hereditary nonpolyposis colorectal cancer (HNPCC,
Lynch syndrome) proposed by the International Collaborative group on HNPCC. Gastroenterology. 1999;116:1453-6.

5. Umar A, Boland CR, Terdiman JP, Syngal S, de la Chapelle A, Ruschoff J, et al. Revised Bethesda Guidelines for hereditary nonpolyposis colorectal cancer (Lynch syndrome) and microsatellite instability. J Natl Cancer Inst. 2004;96:261-8.

6. Rodriguez-Bigas MA, Cutait R, Lynch PM, Tomlinson I, Vasen HF. Hereditary colorectal cancer. New York: Springer; 2010. p. 535-44.

7. Barrow E, Alduaij W, Robinson L, Shenton A, Clancy T, Lalloo F, et al. Colorectal cancer in HNPCC: cumulative lifetime incidence, survival and tumour distribution. A report of 121 
families with proven mutations. Clin Genet. 2008;74:233-42.

8. de Vos tot Nederveen Cappel WH, Jarvinen HJ, Lynch PM, Engel C, Mecklin JP, Vasen HF. Colorectal surveillance in Lynch syndrome families. Fam Cancer. 2013;12:261-5.

9. Schofield L, Grieu F, Amanuel B, Carrello A, Spagnolo D, Kiraly C, et al. Population-based screening for Lynch syndrome in Western Australia. Int J Cancer. 2014;135:1085-91.

10. Sturgeon D, McCutcheon T, Geiger TM, Muldoon RL, Herline $\mathrm{AJ}$, Wise PE. Increasing Lynch syndrome identification through establishment of a hereditary colorectal cancer registry. Dis Colon Rectum. 2013;56:308-14.

11. Barrow P, Khan M, Lalloo F, Evans DG, Hill J. Systematic review of the impact of registration and screening on colorectal cancer incidence and mortality in familial adenomatous polyposis and Lynch syndrome. Br J Surg. 2013;100:1719-31.

12. Mallinson EK, Newton KF, Bowen J, Lalloo F, Clancy T, Hill J, et al. The impact of screening and genetic registration on mortality and colorectal cancer incidence in familial adenomatous polyposis. Gut. 2010;59:1378-82.

13. Park JG, Vasen HF, Park YJ, Park KJ, Peltomaki P, de Leon MP, et al. Suspected HNPCC and Amsterdam criteria II: evaluation of mutation detection rate, an international collaborative study. Int J Colorectal Dis. 2002;17:109-14.

14. Edge SB, Byrd DR, Compton CC, Fritz AG, Greene FL, Trotti A 3rd. AJCC cancer staging manual. 7th ed. New York: Springer-Verlag; 2010.

15. Barrison AF, Smith C, Oviedo J, Heeren T, Schroy PC 3rd. Colorectal cancer screening and familial risk: a survey of internal medicine residents' knowledge and practice patterns. Am J Gastroenterol. 2003;98:1410-6.

16. Park J, Lee SY, Kim DW, Kang SB, Jeong SY, Park KJ. Knowledge of and practice patterns for hereditary colorectal cancer syndromes in korean surgical residents. Ann Coloproctol.
2013;29:186-91.

17. Brixen LM, Bernstein IT, Bulow S, Ehrnrooth E. Survival of patients with Stage III colon cancer is improved in hereditary non-polyposis colorectal cancer compared with sporadic cases. A Danish registry based study. Colorectal Dis. 2013;15:816-23.

18. de Jong AE, Hendriks YM, Kleibeuker JH, de Boer SY, Cats A, Griffioen $G$, et al. Decrease in mortality in Lynch syndrome families because of surveillance. Gastroenterology. 2006;130: $665-71$.

19. Vasen HF, Taal BG, Nagengast FM, Griffioen G, Menko FH, Kleibeuker JH, et al. Hereditary nonpolyposis colorectal cancer: results of long-term surveillance in 50 families. Eur J Cancer. 1995;31A:1145-8.

20. Cairns SR, Scholefield JH, Steele RJ, Dunlop MG, Thomas HJ, Evans GD, et al. Guidelines for colorectal cancer screening and surveillance in moderate and high risk groups (update from 2002). Gut. 2010;59:666-89.

21. Syngal S, Brand RE, Church JM, Giardiello FM, Hampel HL, Burt RW, et al. ACG clinical guideline: Genetic testing and management of hereditary gastrointestinal cancer syndromes. Am J Gastroenterol. 2015;110:223-62.

22. Win AK, Parry S, Parry B, Kalady MF, Macrae FA, Ahnen DJ, et al. Risk of metachronous colon cancer following surgery for rectal cancer in mismatch repair gene mutation carriers. Ann Surg Oncol. 2013;20:1829-36.

23. Rodriguez-Bigas MA, Moeslein G. Surgical treatment of hereditary nonpolyposis colorectal cancer (HNPCC, Lynch syndrome). Fam Cancer. 2013;12:295-300.

24. Haanstra JF, de Vos Tot Nederveen Cappel WH, Gopie JP, Vecht J, Vanhoutvin SA, Cats A, et al. Quality of life after surgery for colon cancer in patients with Lynch syndrome: partial versus subtotal colectomy. Dis Colon Rectum. 2012;55:653-9. 